\title{
Above and beyond meat: the role of consumers' dietary behavior for the purchase of plant-based food substitutes
}

\author{
Cristopher Siegfried Kopplin ${ }^{1}$ D . Theresa Maria Rausch ${ }^{1}$
}

Received: 4 December 2020 / Accepted: 22 June 2021 / Published online: 3 July 2021

(c) The Author(s) 2021

\begin{abstract}
Shrinking meat intake levels and simultaneously increasing consumption of plantbased products among consumers suggest that consumers' dietary behavior implies the purchase of plant-based food substitutes. We contribute to the literature by investigating the most important determinants of consumers' dietary behavior and attitude towards plant-based food substitutes and whether consumers' dietary behavior is of relevance for the attitude towards plant-based food substitutes. Data of 1,363 consumers was used for structural equation modeling as well as necessary condition analysis. Consumers' dietary behavior is found to play only a minor role in attitude formation towards plant-based food substitutes. Dietary behavior is primarily influenced by animal welfare concerns. We did not find environmental concerns, consumers' perceived effectiveness, and health consciousness to influence dietary behavior. However, as consumers associate a high standard of animal welfare with healthiness and food safety, following a plant-based diet due to animal welfare concerns might be an altruistic pretext for health consciousness as an egoistic motive.
\end{abstract}

Keywords Dietary behavior - Structural equation modeling $\cdot$ Necessary condition analysis $\cdot$ Plant-based food substitutes $\cdot$ Health $\cdot$ Environmental concerns $\cdot$ Animal welfare

JEL Classification $\mathrm{M} 10 \cdot \mathrm{M} 30 \cdot \mathrm{O} 30 \cdot \mathrm{Q} 01$

Cristopher Siegfried Kopplin

cristopher.kopplin@uni-bayreuth.de

Theresa Maria Rausch

theresa.rausch@uni-bayreuth.de

1 Chair of Marketing and Innovation, Universitätsstraße 30, 95447 Bayreuth, Germany 


\section{Introduction}

Throughout past years, consumers' dietary behavior is shifting in terms of a steadily decreasing meat intake and increasing consumption of plant-based products: meat consumption continues to sink in large European countries like Germany, France, and Italy (Agriculture and Agri-Food Canada 2017). Simultaneously, the plant-based food market increased by $29 \%$ from 3.9 billion US dollars to 5.0 billion US dollars from 2017 to 2019 in the US alone (PBFA and GFI 2020), and meat substitute sales are expected to continue to grow in Germany with a value of 255.6 million US dollars in 2020 (Agriculture and Agri-Food Canada 2017). This increase in plant-based food substitute market value and the simultaneous decline in meat intake suggests that the concept of consumers' dietary behavior is closely related to the purchase of plant-based food substitutes. As omnivores frequently associate a plant-based diet with negative attributes (e.g., negative stereotypes or nutritional deficiencies) (Lea and Worsley 2001; Pohjolainen et al. 2015), it appears likely that only vegetarians and vegans are interested in purchasing plant-based food substitutes. However, research found consumers with a high nutritional knowledge to exhibit a negative attitude towards meat (Shepherd and Towler 2007) and hence, health-conscious individuals with a lower meat intake level may also be targeted by plant-based substitutes. Hence, it remains unclear whether consumers' dietary behavior is of relevance in the context of plant-based food substitutes.

Further, to gather a better understanding of the impact of consumers' dietary behavior on plant-based food substitutes, the primary motives for a consumer's dietary behavior need to be investigated. Exploratory research found healthrelated (Dyett et al. 2013; Janssen et al. 2016; Lea et al. 2006b), environmental-related (Janssen et al. 2016; Mullee et al. 2017), and animal welfare-related aspects (Mullee et al. 2017) to be the main benefits associated with a plant-based diet. However, contrary findings were gathered among omnivores, linking a plantbased diet with nutrient deficiencies (Corrin and Papadopoulos 2017; Lea et al. 2006a; Lea and Worsley 2001; Pohjolainen et al. 2015) and refusing to reduce meat consumption due to health reasons (Boer et al. 2017). Similarly, environmental impact only played a negligible role for dietary behavior in some studies (Fox and Ward 2008; Povey et al. 2001). Apparently, determinants of consumers' dietary behavior and plant-based food substitute purchase behavior are still not fully understood.

We thus contribute to the literature by investigating whether consumers' dietary behavior is determined by different altruistic or egoistic motives or perceived consumers' effectiveness, and whether consumers' dietary behavior is of relevance for the attitude towards plant-based food substitutes. We compile and test a model based on the Theory of Reasoned Action (TRA) (Ajzen and Fishbein 1980; Fishbein and Ajzen 1975), and employ structural equation modeling using partial least squares (PLS-SEM). As a result, we expect to identify factors that are sufficient to shift consumers' diet towards being plant-based and examine the linkage between dietary behavior and attitude towards plant-based 
food substitutes. PLS-SEM is complemented with a necessary condition analysis (NCA) (Dul 2016a) to gain further insights into the potential necessity of factors. To combine both approaches, we draw on the procedure recently suggested in the PLS literature and use latent variable scores as input for NCA (Richter et al. 2020).

The remainder of this study is structured as follows: We first outline the relevant theoretical background, then describe our methodology, and report our results. Section 5 first merges and discusses the findings of both PLS-SEM as well as NCA and then depicts our theoretical contribution and practical implications. Section 6 draws concluding remarks and outlines limitations as well as directions for future research.

\section{Theoretical background}

\subsection{Theory of reasoned action}

For decades, researchers draw on the TRA (Ajzen and Fishbein 1980; Fishbein and Ajzen 1975) to explain an individual's behavior. At its core, the TRA assumes behavior to be determined by an individual's behavioral intention to exhibit the respective behavior. Behavioral intention, in turn, is influenced by both an intrinsic (i.e., attitudinal) as well as an extrinsic (i.e., social) component. The former aspect, an individual's attitude towards a behavior, is assumed to be a function of the individual's behavioral beliefs about the likelihood of the behavior's consequences and the evaluation of these consequences. The latter aspect, subjective norm, is a function of normative beliefs regarding what the individual's relevant others think about the behavior and the individual's motivation to comply with this evaluation. However, the influence of attitude and subjective norm on intention is not always equal: Depending on the specific behavior, the situation, and individual differences of the actor, the strength of the impact of the attitudinal and normative component on behavioral intention varies (Ajzen and Fishbein 1980).

The TRA predicts primarily volitional behavior, i.e., behavior over which the individual completely has control, or behavior which does not require skills, opportunities, or cooperation of others (Ajzen 1988; Fishbein and Ajzen 1975; Webb and Sheeran 2006). However, behavior is often assumed to be neither entirely volitional nor entirely involitional but ranges in between (Liska 1984). Thus, the Theory of Planned Behavior (TPB) added the concept of perceived behavioral control and incorporated factors internal (e.g., skills or abilities) and external (e.g., time or opportunity) to the person (Ajzen 1985, 1988). It captures the individual's beliefs about how easy or difficult the behavior's performance is assumed to be (Ajzen and Madden 1986). Therefore, it is frequently compared to the notion of self-efficacy (Ajzen 1991; Ajzen and Madden 1986; Bandura 1982).

Both the TRA and the TPB (or extracts) were used to elucidate the purchase behavior of green products in general (Chan 2001; Jaiswal and Kant 2018; Kautish et al. 2019; Yadav and Pathak 2016, 2017) as well as of organic food (Michaelidou and Hassan 2008; Singh and Verma 2017; Smith and Paladino 2010; Vermeir and 
Verbeke 2006, 2008). We thus draw on the TRA to elucidate the purchase intention of plant-based substitutes:

H1: Attitude towards plant-based food substitutes has a positive impact on purchase intention for plant-based food substitutes.

$\mathrm{H} 2$ : Subjective norm has a positive impact on purchase intention for plant-based food substitutes.

\subsection{Consumers' dietary behavior}

The intrinsic component of purchase intention, i.e., attitude, towards specific food products (such as plant-based food substitutes) may strongly depend on the consumer's diet. Research found the main barriers towards a plant-based diet among omnivores to be health concerns about vegetarianism, such as nutrient deficiencies (Corrin and Papadopoulos 2017; Lea et al. 2006a; Lea and Worsley 2001; Pohjolainen et al. 2015), convenience and habit in terms of food neophobia (Corrin and Papadopoulos 2017; Lea et al. 2006a; Lea and Worsley 2001; Pohjolainen et al. 2015), social concerns such as negative stereotypes (Lea and Worsley 2001), and hedonic barriers such as meat enjoyment (Corrin and Papadopoulos 2017; Lea et al. 2006a; Lea and Worsley 2001; Pohjolainen et al. 2015). Consequently, such consumers may consider plant-based food substitutes unnecessary and exhibit a rather negative attitude towards such products.

Thus, it appears likely that plant-based food substitutes may be particularly of interest for vegan and vegetarian consumers or individuals with specific allergies. However, extant research found health-conscious individuals with a high nutritional knowledge to have a negative attitude towards meat products (Shepherd and Towler 2007) and, thus, even non-vegetarian but health-conscious consumers with lower meat intake levels may have a positive attitude towards such plant-based products. Nevertheless, paradoxically, low meat-eating consumers were found to be unwilling to give up meat consumption entirely due to health reasons (Boer et al. 2017). We thus hypothesize:

H3: A consumer's dietary behavior (in terms of a plant-based diet) has a positive impact on attitude towards plant-based food substitutes.

\subsection{Altruistic motives: environmental concerns and animal welfare concerns}

Within the literature, an individual's degree of emotional attachment to environmental problems and its enduring beliefs and feelings about the environment are referred to as the individual's ecological affect or environmental concerns (Chan 2001; Maloney et al. 1975; Weigel and Weigel 1978). An overview of studies employing environmental concerns suggests that attitude as well as green behavior can be predicted using this variable (Kautish and Sharma 2019; Sharma and Joshi 2017). Sophisticated approaches provide a granular depiction of the concept, and assume environmental concerns to reflect three facets: Mostly, consumers' environmental concerns are referred to as a social-altruistic value orientation and imply that "an individual would bear personal costs to safeguard the environment only when doing so would protect other human 
beings" (Stern et al. 1993). However, if environmental concerns were based on selfinterest and egoistic value orientation, an individual would only feel responsible for protecting the environment if the expected benefit for the individual itself outweighed the expected costs (Stern et al. 1993). The third dimension of environmental concerns comprises an individual's biospheric values: the individual would express concerns regarding other species and their habitat but would be unconcerned when environmental issues only affect other humans (Stern et al. 1993). Notwithstanding the construct's different conceptualizations, environmental concerns were frequently found to determine an individual's attitude towards green products (Chan 2001; Goh and Balaji 2016; Mostafa 2007; Prakash and Pathak 2017; Yadav and Pathak 2016) and organic food (Smith and Paladino 2010; Thogersen 2009), assuming that attitude comprises both cognitive as well as affective components (Ajzen 2001; Ajzen and Driver 1991; Petty et al. 1991).

Environmental concerns were found to be among the major motives to follow a vegan or vegetarian diet (Janssen et al. 2016). Even omnivores stated the environmental impact to be the main reason to eat a vegetarian diet (Mullee et al. 2017). However, other studies found environmentalism to play a minor role with respect to dietary behavior (Fox and Ward 2008; Povey et al. 2001) and further indicated a lack of awareness regarding the environmental impact of meat consumption (Macdiarmid et al. 2016).

We thus hypothesize:

H4A: Environmental concerns have a positive impact on attitude towards plantbased food substitutes.

H4B: Environmental concerns have a positive impact on consumer's dietary behavior (in terms of a plant-based diet).

Aside from environmental concerns, animal welfare concerns are a crucial altruistic facet to potentially influence both diet as well as attitude towards plant-based food substitutes. Animal welfare concerns cover both social and nutritional aspects (Hughner et al. 2007), as consumers draw on the standard of animal welfare as an indicator of food safety and healthiness (Harper and Makatouni 2002). Consumers associate, e.g., organic food with the humane treatment of animals (Harper and Makatouni 2002), and thus, a high standard of animal well-being is a motive for buying organic food (Hill and Lynchehaun 2002). Moreover, Jabs et al. (1998) described ethical vegetarians as a group of consumers being motivated to follow a vegetarian diet to align their diet with their beliefs and values about animal welfare. Even omnivores named animal welfare to be a major motive to follow a vegetarian diet (Mullee et al. 2017). We, therefore, derive the following hypotheses:

H5A: Animal welfare concerns have a positive impact on attitude towards plantbased food substitutes.

H5B: Animal welfare concerns have a positive impact on consumer's dietary behavior (in terms of a plant-based diet). 


\subsection{Egoistic motive: health consciousness}

Health-conscious consumers are highly involved in healthy behavior and disease prevention, as they are concerned about their well-being and, thus, tend to have high nutritional knowledge (Gould 1988; Kraft and Goodell 1993; Newsom et al. 2005). Health consciousness was found to be the key motive to purchase organic food (Davies et al. 1995; Magnusson et al. 2001; Squires et al. 2001; Tregear et al. 1994) and further, the most important reason among omnivores to change consumption habits in terms of eating less meat (Latvala et al. 2012) as well as to eat an entirely vegetarian diet (Mullee et al. 2017). Health and disease prevention were found to be the main benefit associated with a plant-based diet (Lea et al. 2006b). Jabs et al. (1998) classified health vegetarians as driven by an enduring perceived threat of disease and potential health benefits associated with a plantbased diet.

Health consciousness can thus not only be assumed to be one of the primary determinants of an individual's diet (Dyett et al. 2013) but further to be a cognitive component of an individual's attitude towards plant-based food substitutes: as a plant-based diet is associated with healthiness and disease prevention (Lea et al. 2006b), health-conscious consumers are expected to exhibit a positive attitude towards plant-based substitutes. We, therefore, derive the following hypotheses:

H6A: Health consciousness has a positive impact on attitude towards plantbased food substitutes.

H6B: Health consciousness has a positive impact on consumers' dietary behavior (in terms of a plant-based diet).

\subsection{Perceived consumer effectiveness}

Perceived consumer effectiveness comprises an individual's beliefs about whether his or her actions affect the environment and whether he or she can do anything to decrease his or her impact (Kinnear et al. 1974; Roberts 1996; Webster 1975). The concept is closely related to the concept of socially conscious (or responsible) consumers (Anderson and Cunningham 1972; Antil 1984) and self-efficacy (Bandura 1982; Vermeir and Verbeke 2008). Initially, perceived consumer effectiveness was treated equivalent to attitude (Antil 1984; Kinnear et al. 1974; Webster 1975), but further studies modeled attitude and perceived consumer effectiveness as two distinct constructs (Ellen et al. 1991): while attitude is considered an evaluation of an individual's beliefs and feelings about an object, perceived consumer effectiveness is the evaluation of the individual's self in the respective context (Berger and Corbin 1992). Drawing on this conceptualization with perceived consumer effectiveness as a stand-alone construct, it was frequently considered one of the central antecedents of an individual's attitude in green and organic food literature (Jaiswal and Kant 2018; Vermeir and Verbeke 2006), and has been verified as a determinant for pro-environmental behavior (Kautish and Sharma 2020; Park and Lin 2018; Taufique and Vaithianathan 2018). Further, the 


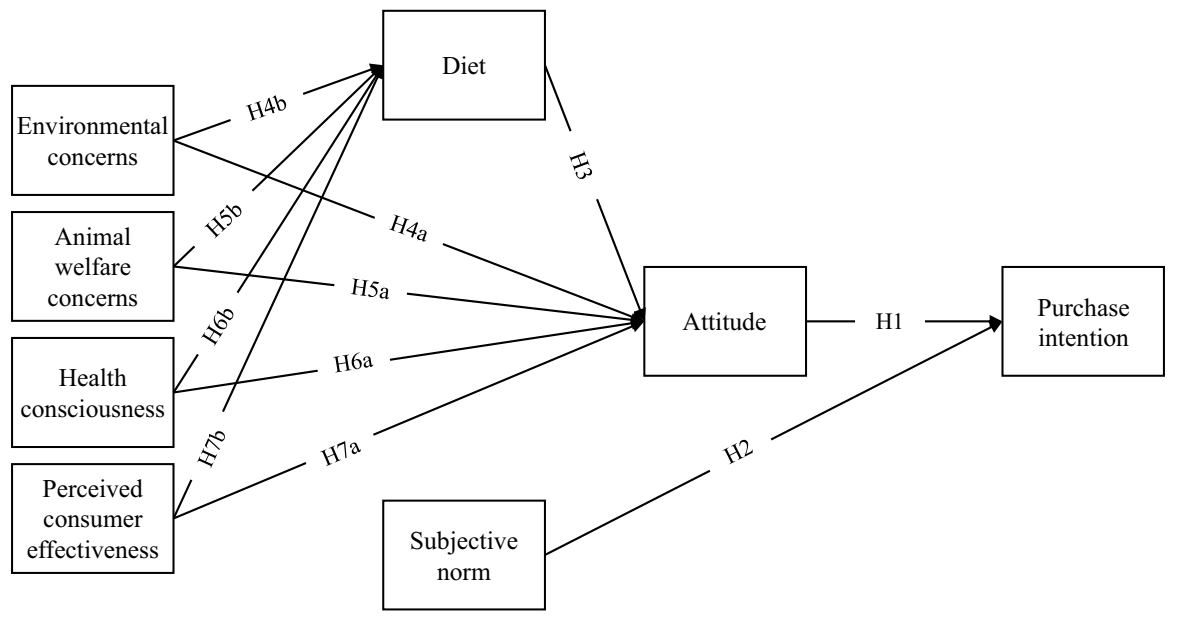

Fig. 1 Research model and hypotheses

individual's belief about whether his or her actions and consumption behavior enhance environmental protection may influence his or her dietary behavior. We hence hypothesize:

H7A: Perceived consumer effectiveness has a positive impact on attitude towards plant-based food substitutes.

H7B: Perceived consumer effectiveness positively impacts consumers' dietary behavior (in terms of a plant-based diet).

Figure 1 depicts the final research model.

\section{Methodology}

\subsection{Conceptualization}

We designed an online questionnaire comprising three major sections: The first part inquired respondents' dietary behavior (i.e., omnivore, flexitarian, pescetarian, vegetarian, mostly vegan, vegan), allergies, and meat consumption frequency (ranging from 'never' to 'daily' on a five-point scale). In the main part, respondents assessed the constructs' items. All items were measured on a five-point Likert-type scale from 'Strongly disagree' $=1$ to 'Strongly agree' $=5$. The altruistic motives, animal welfare concerns, and environmental concerns were measured with scales derived from Hill and Lynchehaun (2002) and Harper and Makatouni (2002) as well as Lee (2008) and Dunlap et al. (2000) respectively. The egoistic motive health consciousness was measured with items from Schifferstein and Oude Ophuis (1998). Items for perceived consumer effectiveness were adopted from Roberts (1996) and Webster (1975). Subjective norm was assessed with items of Ajzen and Madden (1986). For the measurement of purchase intention, we utilized the scales of Tarkiainen and Sundqvist (2005) as well as Michaelidou and Hassan (2008). Only attitude 
was measured with semantic-differential scales of Taylor and Todd (1995), which were adapted from Ajzen $(1985,1991)$ and Ajzen and Fishbein (1980). Appendix B provides all items. The questionnaires' last part inquired about the respondents' demographics.

\subsection{Data collection and descriptive statistics}

Data collection was conducted over five weeks in July and August 2020. Qualtrics was used to capture the responses. In total, 1793 questionnaires were collected. After removing incompletes, 1442 observations were retained. Checking for straightliners and speeders, it was not necessary to exclude data points.

The respondents' age ranged between 15 and 78, with a mean of 25.55 years and a standard deviation of 7.97. However, assessing quartiles and the median value revealed that the sample primarily consists of participants in their twenties (lower quartile $=21$, median $=24$, upper quartile $=27$ ). Hence, the sample appears to correspond to Generation Y roughly. Still, outlier detection was based on standard statistical techniques, and observations exceeding 1.5 standard deviations were excluded. Consequently, 79 data points above the age threshold of 37 were omitted. Thus, in total, 1363 questionnaires were used for analysis. The majority of participants were women $(\mathrm{n}=1276,93.6 \%)$. Our sample comprises 341 omnivores $(25.0 \%), 412$ flexitarians $(30.2 \%)$, eight pescetarians $(0.6 \%), 415$ vegetarians $(30.4 \%)$, nine mostlyvegans $(0.7 \%)$, and 178 vegans $(13.1 \%)$. Most participants indicated having no food intolerance $(n=1,037,76.1 \%)$, and 140 participants indicated to be lactose intolerant $(10.3 \%)$. Two hundred ninety-seven respondents $(21.8 \%)$ are eating meat several times per week, and only 11 respondents $(0.8 \%)$ indicated to eat meat daily. Most participants' income $(\mathrm{n}=360,26.4 \%)$ is between 501 and 1000 Euros and the majority of the respondents are students $(n=715,52.5 \%)$.

\section{Results}

\subsection{Measurement model evaluation}

PLS-SEM is employed for model calculation, and the SmartPLS 3.3.2 software was used (Ringle et al. 2015). As we focus on verifying our model structure and testing hypotheses, as opposed to prediction, we employ the consistent PLS algorithm (Dijkstra and Henseler 2015). The calculation is carried out using a path weighting scheme with 300 maximum iterations and a stop criterion of $10^{-7}$. Convergence was reached after five iterations.

An assessment of the outer loadings, calculated through confirmatory composite analysis (Hair et al. 2020), reveals that five indicators fall short of the recommended threshold of 0.708 (Hair et al. 2019), which are AWEL2 (outer loading =0.494), ECON1 (0.622), HCON1 (0.656), HCON3 (0.524), and SNORM2 (0.696). Albeit the constructs' validity and reliability could be confirmed by drawing on Cronbach's Alpha, composite reliability, and the average variance extracted (AVE) (Benitez 
Table 1 Assessment of convergent validity and internal consistency reliability

\begin{tabular}{lllll}
\hline & Cronbach's alpha & $\rho_{\mathrm{A}}$ & Composite reliability & AVE \\
\hline ATT & $0.925[0.915,0.933]$ & $0.926[0.916,0.934]$ & $0.925[0.915,0.933]$ & $0.804[0.782,0.823]$ \\
AWEL & $0.846[0.830,0.861]$ & $0.848[0.830,0.862]$ & $0.847[0.830,0.861]$ & $0.649[0.620,0.675]$ \\
DIET & Single-item & Single-item & Single-item & Single-item \\
PCE & $0.881[0.865,0.895]$ & $0.882[0.865,0.895]$ & $0.881[0.865,0.895]$ & $0.712[0.681,0.740]$ \\
PI & $0.917[0.904,0.929]$ & $0.928[0.917,0.937]$ & $0.919[0.906,0.930]$ & $0.741[0.711,0.770]$ \\
SNORM & $0.778[0.753,0.801]$ & $0.784[0.755,0.807]$ & $0.782[0.756,0.804]$ & $0.545[0.508,0.578]$ \\
ECON & $0.835[0.816,0.853]$ & $0.846[0.826,0.862]$ & $0.837[0.818,0.855]$ & $0.565[0.532,0.597]$ \\
HCON & $0.805[0.786,0.822]$ & $0.837[0.813,0.865]$ & $0.803[0.783,0.822]$ & $0.515[0.485,0.544]$ \\
\hline
\end{tabular}

DIET is a single-item construct. Ninety-five percent confidence interval (bias-corrected and accelerated) in parentheses

ATT attitude towards plant-based food substitutes, AWEL animal welfare concerns, DIET consumers' dietary behavior, ECON environmental concerns, $H C O N$ health consciousness, $P C E$ perceived consumer effectiveness, $P I$ purchase intention, SNORM subjective norm

et al. 2020), AWEL2 is removed from the outer model. As all constructs pass the recommended threshold for validity and reliability, the remaining indicators are kept in the model. A bootstrapping procedure with 10,000 draws is used to derive 95 percent confidence intervals for each of the criteria, confirming that they neither fall short nor exceed their acceptable ranges ( 0.70 to 0.95 for Cronbach's Alpha, composite reliability, and $\rho_{\mathrm{A}}$, higher than 0.50 for AVE) (Henseler et al. 2016). Table 1 summarizes the results. The empirical covariance matrix is provided in Appendix A. Appendix B provides the items' loadings.

To ensure discriminant validity, the Fornell-Larcker criterion, an evaluation of cross-loadings, and the heterotrait-monotrait ratio (HTMT) (Henseler et al. 2015) are used. For the HTMT ratio, HTMT $_{\text {inference }}$ is calculated using bootstrapping with 10,000 draws. All 95 percent confidence intervals are far off the null value of 1 ,

Table 2 Assessment of discriminant validity (HTMT ratios)

\begin{tabular}{|c|c|c|c|c|c|c|c|c|}
\hline & ATT & AWEL & DIET & ECON & $\mathrm{HCON}$ & PCE & PI & SNORM \\
\hline \multicolumn{9}{|l|}{ ATT } \\
\hline AWEL & 0.398 & & & & & & & \\
\hline DIET & 0.455 & 0.651 & & & & & & \\
\hline ECON & 0.400 & 0.416 & 0.366 & & & & & \\
\hline $\mathrm{HCON}$ & 0.270 & 0.428 & 0.288 & 0.311 & & & & \\
\hline PCE & 0.651 & 0.389 & 0.403 & 0.403 & 0.302 & & & \\
\hline PI & 0.850 & 0.438 & 0.511 & 0.441 & 0.246 & 0.607 & & \\
\hline SNORM & 0.369 & 0.279 & 0.256 & 0.268 & 0.174 & 0.275 & 0.390 & \\
\hline
\end{tabular}

ATT attitude towards plant-based food substitutes, AWEL animal welfare concerns, DIET consumers' dietary behavior, ECON environmental concerns, HCON health consciousness, PCE perceived consumer effectiveness, $P I$ purchase intention, SNORM subjective norm 
corroborating discriminant validity (the highest value is 0.874 for the pair PI/ATT; all other values are 0.685 or lower). Computation of the 99 percent confidence intervals moves the upper boundary, i.e., PI/ATT, to 0.882 , with the second-highest value of 0.695. Table 2 displays the HTMT ratios; the Fornell-Larcker criterion and the cross-loadings are provided in Appendices C and D. Discriminant validity could be confirmed and, as such, the assessment of the outer model is complete. Drawing on the Standardized Root Mean Square Residual (SRMR, 0.043) and the Normed Fit Index (NFI, 0.938), the model's structure is verified as well.

\subsection{Structural model evaluation}

The inner model is evaluated drawing on variance inflation factors (VIFs) to check for potential collinearity problems. All values are relatively low and range between 1.157 and 2.021. Consequently, the absence of collinearity issues is assumed (Hair et al. 2019). Common method bias is addressed using the approach suggested by Kock (2015), demanding that in a full collinearity check, all VIF values need to remain below the threshold of 3.3. This assessment is passed, indicating that common method bias is not a threat to the study at hand. Complementary usage of the Harman's single-factors test (Podsakoff and Organ 1986) confirms this result.

To assess the structural model's explanatory power, the coefficient of determination $\left(\mathrm{R}^{2}\right)$ is employed. As Table 3 shows, predictive relevance could be established. Interpretations of $\mathrm{R}^{2}$ values may follow a standardized guideline, as provided in Table 3; however, it is essential to acknowledge that these values are contextdependent. As there is no benchmark from similar studies so far, it is difficult to provide an evaluation. In the case of PI, it is reasonably straightforward to assume a good explanation of variance. For ATT and DIET, about half of the variance could be explained. Regarding that four constructs were used as predictors in both cases, the $\mathrm{R}^{2}$ value may be interpreted as moderate.

After assessing the inner model's properties, hypotheses testing is carried out using bootstrapping with 10,000 draws. Table 4 displays our findings, revealing that most hypotheses, except H5a, H6a, and H6b, could be corroborated. As a result, we found evidence that neither AWEL nor HCON influence ATT (H5a and H6a), and HCON further appears not to impact DIET (H6b).

Using the $\mathrm{f}^{2}$ values to interpret statistically significant relations, PCE has a large effect on ATT, while ECON falls slightly short of being considered a small effect (Hair et al. 2019). Regarding DIET, however, AWEL is the strongest predictor with

Table 3 Explanatory power evaluation

\begin{tabular}{llll}
\hline & $\mathrm{R}^{2}$ value & $\mathrm{R}^{2}$ adjusted & Interpretation \\
\hline ATT & 0.478 & 0.476 & Moderate \\
DIET & 0.456 & 0.454 & Moderate \\
PI & 0.726 & 0.726 & Moderate to substantial \\
\hline
\end{tabular}

Interpretation adopted from Hair et al. (2019)

ATT attitude towards plant-based food substitutes, DIET consumers' dietary behavior, $P I$ purchase intention 
Table 4 Hypotheses testing

\begin{tabular}{llllll}
\hline Hypothesis & & & Path coefficient $\left(\mathrm{f}^{2}\right.$ value) & $\begin{array}{l}\text { 95 percent con- } \\
\text { fidence interval } \\
(\mathrm{BCa})\end{array}$ & $\begin{array}{l}\text { T-value } \\
\text { (p-value) }\end{array}$ \\
\hline H1 & ATT & PI & $0.816(2.101)$ & {$[0.781,0.847]$} & $49.085(<0.001)$ \\
H2 & SNORM & PI & $0.088(0.024)$ & {$[0.046,0.129]$} & $4.177(<0.001)$ \\
H3 & DIET & ATT & $0.190(0.038)$ & {$[0.126,0.250]$} & $5.984(<0.001)$ \\
H4a & ECON & ATT & $0.108(0.017)$ & {$[0.045,0.170]$} & $3.380(0.001)$ \\
H4b & ECON & DIET & $0.075(0.008)$ & {$[0.020,0.127]$} & $2.756(0.006)$ \\
H5a & AWEL & ATT & $0.025(0.001)$ & {$[-0.054,0.107]$} & $0.600(0.548)$ \\
H5b & AWEL & DIET & $0.572(0.423)$ & {$[0.519,0.624]$} & $21.560(<0.001)$ \\
H6a & HCON & ATT & $0.005(<0.001)$ & {$[-0.054,0.060]$} & $0.173(0.862)$ \\
H6b & HCON & DIET & $-0.034(0.002)$ & {$[-0.085,0.018]$} & $1.275(0.202)$ \\
H7a & PCE & ATT & $0.518(0.382)$ & {$[0.456,0.580]$} & $16.432(<0.001)$ \\
H7b & PCE & DIET & $0.161(0.036)$ & {$[0.099,0.217]$} & $5.349(<0.001)$ \\
\hline
\end{tabular}

ATT attitude towards plant-based food substitutes, AWEL animal welfare concerns, DIET consumers' dietary behavior, ECON environmental concerns, HCON health consciousness, PCE perceived consumer effectiveness, $P I$ purchase intention, SNORM subjective norm

a large effect $\left(f^{2}=0.423\right)$, followed by PCE with a small effect $\left(f^{2}=0.036\right)$. ECON does not strikingly influence DIET $\left(\mathrm{f}^{2}=0.008\right)$.

Finally, ATT has a strikingly large impact on PI $\left(\mathrm{f}^{2}=2.101\right)$, and the path coefficient indicates a symmetric relation (0.816) (Woodside 2013). In contrast, the impact of SNORM on PI can be considered small. In total, PI is more substantially shaped by behavioral beliefs (in the form of ATT) than by normative beliefs (in the form of SNORM); however, both influences are statistically convincing. Further, our

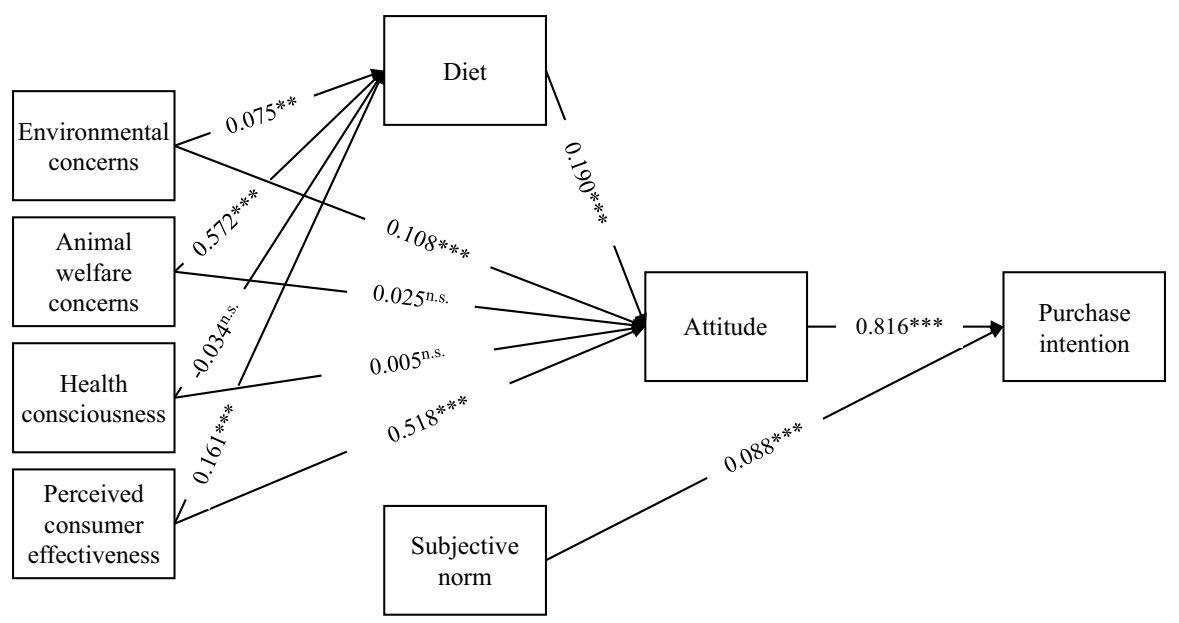

Fig. 2 PLS-SEM results. Note Values indicate path coefficients; ${ }^{* *} p \leq 0.01,{ }^{* * *} p \leq 0.001$, n.s. $=$ not significant 
model can explain DIET reasonably well, finding that AWEL is the most significant factor. Figure 2 provides a more parsimonious depiction of the most fundamental results.

\subsection{Necessary condition analysis}

Consistent with recommendations by Richter et al. (2020), PLS-SEM findings are treated as providing information about the constructs' sufficiency for the outcome. As a complement, NCA (Dul 2016a) is performed using latent variable scores as input (Richter et al. 2020). To do so, we derived scores by using the PLS algorithm for composites (path weighting scheme, 300 maximum iterations, stop criterion of $10^{-7}$ ), and performed the regular assessment we used for the consistent PLS-SEM, which confirmed the viability of both our measurement and our structural model. Our model includes three endogenous variables - ATT, DIET, and PI - and, consequently, three NCAs need to be run. Due to all latent variables being measured reflectively, only the latent variable scores are required in the analyses.

The first NCA run tests for the necessity of AWEL and PCE for the occurrence of ATT. To test the effects for statistical significance, a bootstrapping procedure with 10,000 draws was implemented. For drawing the ceiling line, ceiling regression - free disposal hull (CR-FDH) was used (Dul 2016b). Table 5 summarizes the results.

On a significance level of 0.05, which was also employed for the PLS-SEM, both PCE and AWEL are identified as necessary conditions for ATT. Regarding interpretation recommendations for d, the effects of ECON, HCON, and AWEL may be considered small, while for PCE and DIET, no influence could be detected (Dul 2016b). More detailed insights can be gained from the bottleneck technique, which is provided in Table 6.

As the bottleneck table displays, ECON is the first variable to impose constraints; however, its impact is reasonably weak, with only $8.0 \%$ of the range of ECON being required for ATT to unfold its full potential. Similar observations can be made for HCON (however, its impact is not statistically significant) and AWEL, and in the cases of PCE and DIET, no necessity was identified at all.

Table 5 NCA results for ATT as the outcome

\begin{tabular}{lllccc}
\hline Condition & Observations & Accuracy & p-accuracy & Effect size d & p-value \\
\hline ECON & 1 & $99.9 \%$ & $<0.001$ & 0.029 & 0.002 \\
HCON & 1 & $99.9 \%$ & 0.007 & 0.012 & 0.138 \\
AWEL & 0 & $100.0 \%$ & 0.002 & 0.012 & 0.008 \\
PCE & 0 & $100.0 \%$ & $<0.001$ & $<0.001$ & 1 \\
DIET & 0 & $100.0 \%$ & $<0.001$ & $<0.001$ & 1 \\
\hline
\end{tabular}

Observations indicate the number of data points above the ceiling line

ATT attitude towards plant-based food substitutes, AWEL animal welfare concerns, DIET consumers' dietary behavior, ECON environmental concerns, HCON health consciousness, $P C E$ perceived consumer effectiveness 
Table 6 Bottleneck table for ATT

\begin{tabular}{llllll}
\hline Y & ECON & HCON & AWEL & PCE & DIET \\
\hline 0 & $\mathrm{NN}$ & $\mathrm{NN}$ & $\mathrm{NN}$ & $\mathrm{NN}$ & $\mathrm{NN}$ \\
10 & $\mathrm{NN}$ & $\mathrm{NN}$ & $\mathrm{NN}$ & $\mathrm{NN}$ & $\mathrm{NN}$ \\
20 & $\mathrm{NN}$ & $\mathrm{NN}$ & $\mathrm{NN}$ & $\mathrm{NN}$ & $\mathrm{NN}$ \\
30 & 0.2 & $\mathrm{NN}$ & $\mathrm{NN}$ & $\mathrm{NN}$ & $\mathrm{NN}$ \\
40 & 1.3 & $\mathrm{NN}$ & $\mathrm{NN}$ & $\mathrm{NN}$ & $\mathrm{NN}$ \\
50 & 2.4 & $\mathrm{NN}$ & $\mathrm{NN}$ & $\mathrm{NN}$ & $\mathrm{NN}$ \\
60 & 3.6 & $\mathrm{NN}$ & $\mathrm{NN}$ & $\mathrm{NN}$ & $\mathrm{NN}$ \\
70 & 4.7 & $<0.1$ & $\mathrm{NN}$ & $\mathrm{NN}$ & $\mathrm{NN}$ \\
80 & 5.8 & 2.7 & 1.9 & $\mathrm{NN}$ & $\mathrm{NN}$ \\
90 & 6.9 & 5.4 & 5.7 & $\mathrm{NN}$ & $\mathrm{NN}$ \\
100 & 8.0 & 8.0 & 9.4 & $\mathrm{NN}$ & $\mathrm{NN}$ \\
\hline
\end{tabular}

$N N$ not necessary. $Y$ outcome, i.e., ATT. All values in percent $A T T$ attitude towards plant-based food substitutes, $A W E L$ animal welfare concerns, DIET consumers' dietary behavior, ECON environmental concerns, $H C O N$ health consciousness, $P C E$ perceived consumer effectiveness

Table 7 NCA results for DIET as the outcome

\begin{tabular}{lllcrr}
\hline Condition & Observations & Accuracy & p-accuracy & Effect size d & p-value \\
\hline ECON & 0 & $100.0 \%$ & 0.010 & 0.032 & 0.426 \\
HCON & 1 & $99.9 \%$ & 0.009 & 0.045 & 0.365 \\
AWEL & 2 & $99.9 \%$ & $<0.001$ & 0.233 & $<0.001$ \\
PCE & 0 & $100.0 \%$ & 0.006 & 0.050 & 0.106 \\
\hline
\end{tabular}

Observations indicate the number of data points above the ceiling line

AWEL animal welfare concerns, DIET consumers' dietary behavior, ECON environmental concerns, $H C O N$ health consciousness, $P C E$ perceived consumer effectiveness

The second analysis run seeks to examine the constraint imposed on DIET. Table 7 displays the results, indicating that AWEL has a significant effect on DIET, while all other constructs do not yield striking influence.

Table 8 shows the bottleneck table for DIET as the outcome. For all four variables, constraints can be observed; however, as only AWEL's effect was found to be statistically significant, we deem it adequate to restrict interpretation to this factor. AWEL comes into play for rather small outcome values $(\mathrm{Y}=0.30)$ and quickly gains importance. For example, in the case of $\mathrm{Y}=0.50$ as the desired outcome, 19.5\% of AWEL's range needs to be realized, while for $Y=0.60$, this value increases to about a quarter. For $Y=70$, more than a third is required, and $Y=80$ may only be observed when about half of AWEL's range is in place.

The third and final run examines the occurrence of PI. Table 9 summarizes the results for the bootstrapping procedure, finding ATT to exhibit an impact, while SNORM is identified as not being a necessary condition. 
Table 8 Bottleneck table for DIET

\begin{tabular}{lllll}
\hline Y & ECON & HCON & AWEL & PCE \\
\hline 0 & $\mathrm{NN}$ & $\mathrm{NN}$ & $\mathrm{NN}$ & $\mathrm{NN}$ \\
10 & $\mathrm{NN}$ & $\mathrm{NN}$ & $\mathrm{NN}$ & $\mathrm{NN}$ \\
20 & $<0.1$ & $\mathrm{NN}$ & $\mathrm{NN}$ & $\mathrm{NN}$ \\
30 & 1.0 & $\mathrm{NN}$ & 1.3 & $\mathrm{NN}$ \\
40 & 2.0 & 0.3 & 10.4 & $\mathrm{NN}$ \\
50 & 3.0 & 2.7 & 19.5 & $\mathrm{NN}$ \\
60 & 4.0 & 5.0 & 28.6 & $\mathrm{NN}$ \\
70 & 5.0 & 7.4 & 37.8 & 6.2 \\
80 & 6.0 & 9.8 & 46.9 & 12.5 \\
90 & 7.0 & 12.2 & 56.0 & 18.7 \\
100 & 8.0 & 14.6 & 65.1 & 25.0 \\
\hline
\end{tabular}

$N N$ not necessary. $Y$ outcome, i.e., DIET. All values in percent AWEL animal welfare concerns, DIET consumers' dietary behavior, ECON environmental concerns, HCON health consciousness, $P C E$ perceived consumer effectiveness

Table 9 NCA results for PI as the outcome

\begin{tabular}{llllcc}
\hline Condition & Observations & Accuracy & p-accuracy & Effect size d & $p$-value \\
\hline ATT & 1 & $99.9 \%$ & $<0.001$ & 0.201 & $<0.001$ \\
SNORM & 0 & $100.0 \%$ & $<0.001$ & $<0.001$ & 1 \\
\hline
\end{tabular}

Observations indicate the number of data points above the ceiling line

$A T T$ attitude towards plant-based food substitutes, $P I$ purchase intention, SNORM subjective norm

Table 10 Bottleneck table for PI

\begin{tabular}{lll}
\hline $\mathrm{Y}$ & $\mathrm{ATT}$ & SNORM \\
\hline 0 & $\mathrm{NN}$ & $\mathrm{NN}$ \\
10 & $\mathrm{NN}$ & $\mathrm{NN}$ \\
20 & 2.0 & $\mathrm{NN}$ \\
30 & 7.8 & $\mathrm{NN}$ \\
40 & 13.6 & $\mathrm{NN}$ \\
50 & 19.4 & $\mathrm{NN}$ \\
60 & 25.1 & $\mathrm{NN}$ \\
70 & 30.9 & $\mathrm{NN}$ \\
80 & 36.7 & $\mathrm{NN}$ \\
90 & 42.5 & $\mathrm{NN}$ \\
100 & 48.2 & $\mathrm{NN}$ \\
\hline
\end{tabular}

$N N$ not necessary. $Y$ outcome, i.e., PI. All values in percent $A T T$ attitude towards plant-based food substitutes, $P I$ purchase intention, SNORM subjective norm 
Again, the bottleneck technique is employed for further examination. The results are provided in Table 10. SNORM is found not to yield any constraints at all. ATT, however, imposes constraints even for small values of the outcome and requires moderate values $(30.9-48.2 \%$ of range) to allow high outcome levels to occur.

Altogether, NCA complements the results derived from PLS. First, no evidence for SNORM being a necessary condition could be found, and only a weak (but statistically significant) impact in the role of a sufficient condition was detected.

Altogether, we observe three cases that are both necessary and sufficient conditions: ECON (for ATT; however, both effects are small), AWEL (for DIET, with medium constraints in terms of necessity and a large effect in terms of sufficiency), and ATT (for PI, with medium constraints in terms of necessity and a very large effect in terms of sufficiency). Qualities of sufficiency have further been found for the impact of PCE on ATT (large effect), the impact of PCE on DIET (small effect), the influence of DIET on ATT (small effect), and the influence of SNORM on PI (small effect). Necessity without being a sufficient condition was detected for AWEL's constraint on ATT (small effect). Table 11 integrates our findings.

\section{Discussion}

Regarding the PLS model's results, it is particularly interesting to discuss the explanation of variance. PI could be explained to a satisfactory extent $\left(R^{2}=0.726\right)$, which fits the research model's theoretical underpinning in the form of TRA. ATT was identified as a necessary and sufficient condition for PI, which provides evidence from a novel methodological perspective that TRA's mechanisms offer a valid framework to explain behavioral intentions. Further, the strength of the relation (path coefficient $=0.816$ ) indicates a quasi-symmetric link (Woodside 2013); i.e.,

Table 11 Result summary of both analyses

\begin{tabular}{|c|c|c|c|c|}
\hline \multicolumn{3}{|c|}{ Hypothesis } & \multirow{2}{*}{$\begin{array}{l}\text { Necessary condition } \\
\text { Yes; medium effect }(d=0.201)\end{array}$} & \multirow{2}{*}{$\begin{array}{l}\text { Sufficient condition } \\
\text { Yes; large effect }\left(\mathrm{f}^{2}=2.101\right)\end{array}$} \\
\hline H1 & ATT & PI & & \\
\hline $\mathrm{H} 2$ & SNORM & PI & No & Yes; small effect $\left(\mathrm{f}^{2}=0.024\right)$ \\
\hline $\mathrm{H} 3$ & DIET & ATT & No & Yes; small effect $\left(\mathrm{f}^{2}=0.038\right)$ \\
\hline $\mathrm{H} 4 \mathrm{a}$ & ECON & ATT & Yes; small effect $(d=0.029)$ & Yes; small effect $\left(\mathrm{f}^{2}=0.017\right)$ \\
\hline $\mathrm{H} 4 \mathrm{~b}$ & ECON & DIET & No & No \\
\hline H5a & AWEL & ATT & Yes; small effect $(\mathrm{d}=0.012)$ & No \\
\hline $\mathrm{H} 5 \mathrm{~b}$ & AWEL & DIET & Yes; medium effect $(\mathrm{d}=0.233)$ & Yes; large effect $\left(\mathrm{f}^{2}=0.423\right)$ \\
\hline H6a & $\mathrm{HCON}$ & ATT & No & No \\
\hline H6b & $\mathrm{HCON}$ & DIET & No & No \\
\hline $\mathrm{H} 7 \mathrm{a}$ & PCE & ATT & No & Yes; large effect $\left(\mathrm{f}^{2}=0.382\right)$ \\
\hline $\mathrm{H} 7 \mathrm{~b}$ & PCE & DIET & No & Yes; small effect $\left(f^{2}=0.036\right)$ \\
\hline
\end{tabular}

ATT attitude towards plant-based food substitutes, AWEL animal welfare concerns, DIET consumers' dietary behavior, ECON environmental concerns, HCON health consciousness, PCE perceived consumer effectiveness, $P I$ purchase intention, SNORM subjective norm 
while high values of ATT evoke high values of PI, low values of ATT lead to the opposite. In the sustainability field, symmetric relations are not the norm, and, as such, this finding is fairly surprising.

DIET and ATT could be explained to a moderate extent $\left(\mathrm{R}^{2}\right.$ values of 0.456 and 0.478 , respectively). In both cases, we used the same predictors and achieved very similar results; however, we also included a link between DIET and ATT. This additional influence on ATT leads to the slightly increased $\mathrm{R}^{2}$ in comparison to DIET (without the link, the value decreases to 0.458). Consequently, although the order of independent variables differs in terms of their effect sizes, both ATT and DIET are affected similarly in total. In both cases, HCON yields only a negligible impact. The role of ECON is ambiguous in our data: for DIET, its impact is far below being considered a small effect $\left(\mathrm{f}^{2}=0.008\right)$, and for ATT, although still falling short of the threshold, the miss is reasonably close $\left(f^{2}=0.017\right)$. However, based on interpretation guidelines for effect size, we may conclude that in both cases, ECON does not have a substantial influence. Concerning the remaining two predictors, PCE exhibits the largest effect on ATT but only a small impact on DIET. AWEL does not appear to play a role for ATT; however, it is the most substantial predictor for DIET with a large effect $\left(\mathrm{f}^{2}=0.423\right)$. Altogether, ECON and HCON behave similarly as predictors for ATT and DIET, and PCE and AWEL switch their roles. We explain this alteration as a result of consumers' different perceptions regarding DIET and ATT: individuals that are worried about animal welfare may exert a direct, immediate impact by avoiding meat-based products in their nutrition; however, in the case of ATT, this influence is more indirect in nature, as buying substitutes naturally does not exclude purchasing meat but may be a complement. The link between DIET and ATT provides further evidence, indicating that after having selected nutrition to follow, consumers that decrease or abandon meat intake are willing to try out novel, plant-based products in addition to their current food choice. For ATT, on the other hand, an individual's belief of being able to make a change (i.e., PCE) yields the most substantial influence, which appears reasonable as plant-based food substitutes are not restricted to replacing meat, and instead may also compensate for other products such as honey, milk, and eggs. That is, consumers that are not worried about animal welfare may nevertheless note negative environmental impacts exerted through current practices of large-scale production and seek alternatives.

Consumers' ATT may also be affected by negative framings of meat-based nutrition, such as reports of factory farming and multi-resistant germs, and define plantbased diets as a reasonable alternative. Consequently, adverse beliefs about a meatbased diet, e.g., food safety concerns (Michaelidou and Hassan 2008), could predict ATT as well.

A surprising result is the absence of an effect of AWEL on ATT. It appears reasonable to assume the influence of consumers' concerns for animal welfare on their attitude towards plant-based food substitutes; however, our empirical data did not reveal such a relation. This finding might be explained by the vast amount of vegetarian and vegan groceries that render it optional to consume food substitutes. Consequently, DIET plays only a minor role in shaping individuals' ATT $\left(\mathrm{f}^{2}=0.038\right)$. Still, DIET is not a necessary condition for ATT, indicating that plant-based food substitutes are of interest to consumers regardless of their diet. Similarly, concerns 
for one's health (i.e., HCON) were not found to play any role in intention formation, and, more striking, they do not appear to impact consumers' dietary behavior.

ECON, which captures individuals' environmental concerns, is altruistic in nature and, thus, conceptually close to AWEL. Nevertheless, its impact on ATT is weak, and the influence on DIET is far off being considered even a small effect $\left(\mathrm{f}^{2}=0.008\right)$. This result seems counterintuitive, as factory farming is commonly associated with adverse environmental impact, and similar effects of ECON and AWEL might be assumed. Our results indicate that, against the backdrop of ECON's vanishingly small influence, AWEL may be viewed as an ethical perception as opposed to a more rational, ecological perspective. At large, consumers' intention formation is not about the environment but about avoiding harmful treatment of animals. This conclusion is also supported by the strong impact of AWEL on DIET $\left(\mathrm{f}^{2}=0.423\right)$.

PCE, on the other hand, yields expected results: it does not significantly shape consumers' dietary behavior, as a variety of reasons, such as feeling morally obligated to avoid meat, may impact DIET. The influence on ATT is substantial, indicating that individuals are convinced that their purchase decisions contribute to the environment.

The small influence of social pressure, in the form of SNORM, appears striking. This finding indicates that extrinsic motivation or seeking social approval is not an essential driver of PI. In combination with NCA findings, i.e., SNORM is not a necessary condition for PI, it plays only a minor role.

\subsection{Theoretical implications}

Within this study, we primarily aimed at gathering insights into the determinants of consumers' dietary behavior and the impact of dietary behavior on plant-based food substitutes. Exploratory research provided a first glimpse on the perceived benefits of a plant-based diet (Dyett et al. 2013; Janssen et al. 2016; Lea et al. 2006b; Mullee et al. 2017), but also on the negative associations related to a vegetarian or vegan diet (Corrin and Papadopoulos 2017; Lea et al. 2006a; Lea and Worsley 2001; Pohjolainen et al. 2015). Nevertheless, the importance of the different determinants of dietary behavior and, in turn, its impact on the attitude towards plant-based food substitutes remained unclear.

As extant literature found omnivores to associate a plant-based diet with-inter alia-health concerns (Corrin and Papadopoulos 2017; Lea et al. 2006a; Lea and Worsley 2001; Pohjolainen et al. 2015) and negative stereotypes (Lea and Worsley 2001), it appeared likely that they might not be interested in purchasing plantbased food substitutes. However, we found consumers' dietary behavior to play only a minor role in consumers' attitude formation towards plant-based food substitutes, and thus, omnivores, as well as vegans and vegetarians, are equally interested in purchasing plant-based substitutes. This further aligns with our finding that consumers' dietary behavior is not affected by consumers' health consciousness, i.e., consumers do not choose a specific dietary behavior due to health reasons, contradicting findings of Dyett et al. (2013) and Lea et al. (2006b). Further, health consciousness does not impact consumers' attitude towards plant-based substitutes, which is in contrast 
to preceding findings of the organic food literature (Magnusson et al. 2001; Squires et al. 2001).

Instead, we found animal welfare concerns to be the most important determinant of an individual's dietary behavior; i.e., consumers choose a specific dietary behavior due to ethical considerations with respect to the humane treatment of livestock. However, as many consumers draw on the standard of animal welfare as an indicator of food safety and healthiness (Harper and Makatouni 2002), following a plantbased diet due to animal welfare concerns might be an altruistic excuse for egoistic motives like health concerns. Only a few exploratory studies (Jabs et al. 1998; Mullee et al. 2017) considered animal welfare as a potential determinant of consumers' diet.

Consumers do not follow a certain diet to express their environmental concerns or to protect the environment, aligning with exploratory findings of Fox and Ward (2008) as well as Povey et al. (2001), which found environmental concerns to play only a minor role with respect to dietary behavior. Its effect on attitude towards plant-based food substitutes was only marginal. Nevertheless, consumers' belief to mitigate their environmental impact when purchasing plant-based food substitutes influenced attitude formation, similar to organic food and green literature (Jaiswal and Kant 2018; Vermeir and Verbeke 2008).

\subsection{Practical implications}

Our results suggest several starting points for both organizations offering plantbased food substitutes and policy-makers. As PCE was identified as a major influence on individuals' attitude towards plant-based food, they believe that reducing their meat intake contributes to environmentally friendly behavior. It is important to help consumers make an informed decision about their grocery purchases by providing data on their ecological impact. Organizations may approach this demand through transparent communication of their supply chains, such as $\mathrm{CO}_{2}$ emissions/ carbon footprint, water usage, distance traveled, and other environmentally impactful factors that are easy to grasp and integrate into decision-making. Where it is not feasible to disclose information, e.g., because it is difficult to understand by laypeople, policy-makers may support both organizations and consumers by specifying standardized representation in the form of equivalents. These equivalents may be formulated similarly to 'The amount of water used for production could fill 100 bathtubs' (in the case of one kilogram beef) (Institute of Mechanical Engineers 2013). To facilitate comparisons across various products, it is essential to provide standardized equivalents, which may be ensured by policy-making. Research has also found that organizations following environmentally responsible practices can evoke favorable consumer perceptions and may induce more sustainable behavior (see, e.g., the overview presented in White et al. 2019).

In general, however, sustainable goods frequently suffer from the so-called attitude-behavior gap (Rausch and Kopplin 2021), indicating that consumers' positive attitude towards these products may not translate into action. Hence, from a managerial perspective, it is important to provide boundary conditions that render it 
attractive to purchase sustainable goods. One critical aspect is the products' availability within the channels consumers commonly employ for their purchases, such as local supermarkets. Restricted access such as certain products being only available on the organization's website, thus, is deemed rather counterproductive.

Another critical aspect is that of habit-human beings are creatures of habit. Organizations may make use of this fact by inducing purchases for test purposes to establish a first consumer contact with the plant-based food substitute. Such purchases may be elicited through social media campaigns embracing a dedicated hashtag or featuring consumer posts as a part of the organization's online appearance, e.g., on Instagram. Other possibilities are lotteries, preferably ones utilizing precise settings such as a holiday season theme, and in-store sales stalls.

Interestingly, consumers' dietary behavior is not a necessary condition for a positive attitude towards plant-based food substitutes, and further, its influence is also reasonably small. Consequently, individuals may be viewed as potential buyers regardless of their dietary choices, and plant-based food substitutes appear not to be restricted to a market niche.

In the case of social influences (captured in the form of SNORM), which is neither a necessary condition nor yields substantial effects on an individual's purchase intention, it appears justifiable from a managerial perspective to neglect the variable. However, as green consumption increases, it may well be the case that social influences gain traction and serve, e.g., as a basis for social comparisons, and there is research from other sustainability contexts that find social influence to play a role (Abrahamse and Steg 2013). Organizations creating awareness through marketing campaigns, particularly employing social media channels, enable social processes to kick in, such as spreading word-of-mouth, and may yield benefits when sustainable food in general and plant-based food substitutes, in particular, have become household goods. Still, it is important to bear in mind that the impact of social influences was less substantial than behavioral beliefs, and as such, the latter should be emphasized.

As consumers' dietary behavior is primarily affected by consumers' concerns for animal welfare, producers, and retailers of vegan and vegetarian products should bear that in mind and adapt their marketing claims. However, as consumers associate a high standard of animal welfare with healthy products, marketers should link animal welfare claims with health claims.

\section{Conclusion}

Within this study, we found evidence that consumers' dietary behavior only slightly influences consumers' attitude towards plant-based food substitutes, and thus, all dietary groups may be targeted by the plant-based food substitute industry. Concerns for animal welfare exhibited the largest effect on consumers' dietary behavior, whereas environmental concerns and health consciousness did not impact dietary behavior.

Regarding the purchase intention for plant-based food substitutes, consumers' intrinsic motive (i.e., attitude) was strikingly strong. Among the respective behavioral beliefs, 
individuals' perceived consumer effectiveness, i.e., their impression of being able to make a change depending on their purchase decisions, showed a large influence on consumers' attitude towards plant-based food substitutes. These behavioral beliefs were accompanied by normative beliefs (i.e., the extrinsic motive in the form of subjective norm), indicating that the social surrounding also plays a role, although a reasonably small one, in purchasing plant-based food substitutes. We might expect this effect to increase over time, as plant-based food substitutes become common parts of daily nutrition.

\section{Limitations and future research opportunities}

Nevertheless, some limitations need to be addressed. While our sample is quite large, we find it fairly homogeneous, as it primarily consists of female students and young professionals in their twenties. Consequently, our findings of intrinsic motivation being an important driver of dietary behavior and purchase intention concerning plant-based food substitutes, while social influences do not play a vital role, need to be handled with care. It is likely that a different sample that represents, e.g., the whole German population finds lower proportions of individuals that consider themselves vegetarians or vegans. Further, it is possible that consumer groups less involved in the social media sphere, where green consumption is an increasingly prominent topic, may yield a lower awareness and less information, and thus be more hesitant regarding the purchase of plant-based food substitutes. A sample that is balanced considering gender may also find a shift in the average assessment, probably towards lower values of environmental concerns and altruistic motives in general, as men are commonly less agreeable than women (Weisberg et al. 2011).

It may well be the case that young people with high education, who represent a vast majority of our sample, yield motivations that differ from other social groups. Hence, social processes should not be neglected in future research but treated as a possible discriminant. Also, we used a multivariate, large- $\mathrm{N}$ approach, which provides insights on a general level but neglects details on the individual level. As is typical for such applications, we captured the responses using self-report scales, which may impose a social desirability bias. Many participants indicated a plant-focused or even entirely plant-based diet and may give similar responses to environmental-related questions to align their answers with their life style.

Future research could also address the interdependence between animal welfare concerns and health considerations. As we already claimed in the discussion, following a plant-based dietary behavior due to animal welfare concerns might just be an altruistic pretext for health concerns as an egoistic motive. 


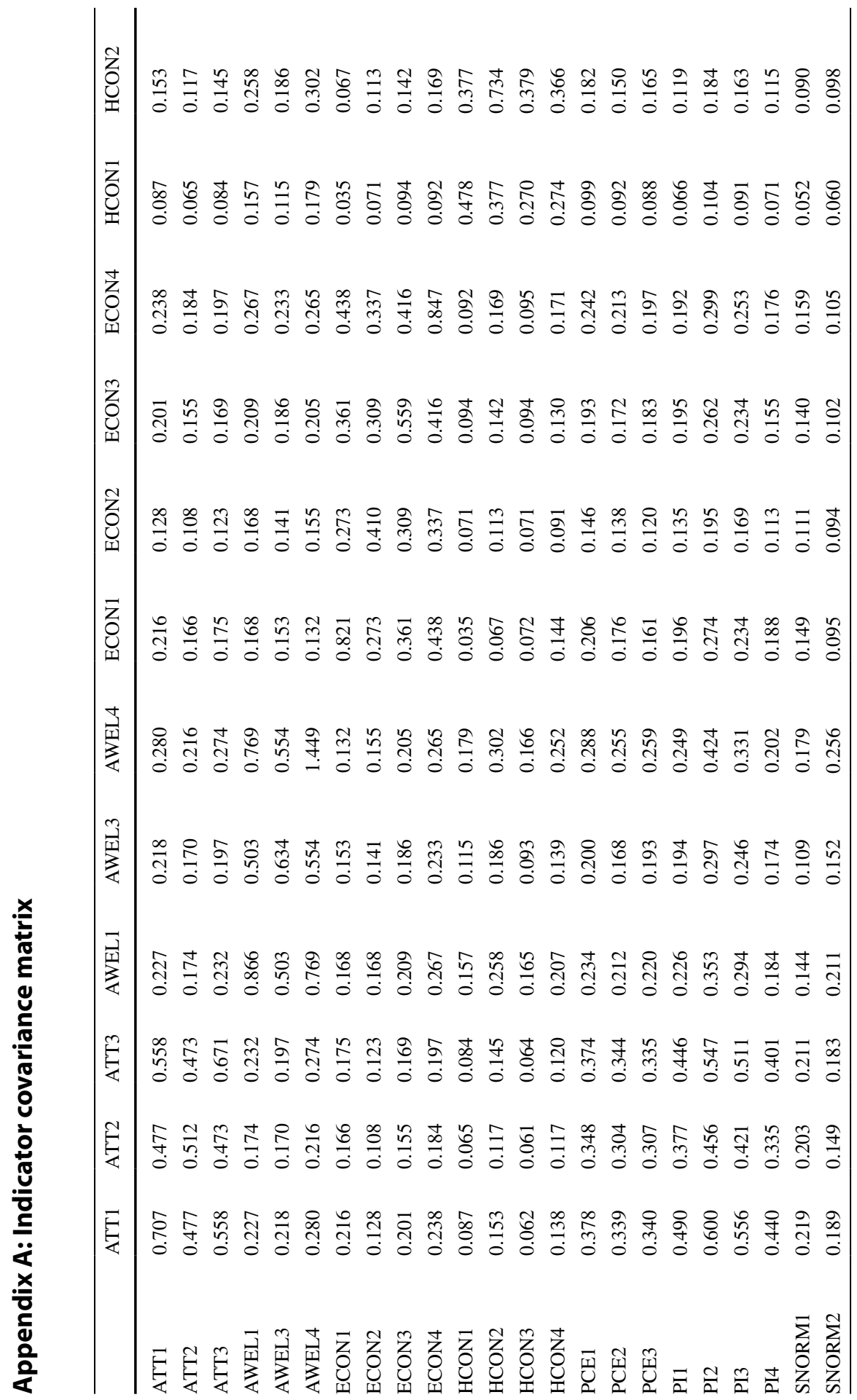




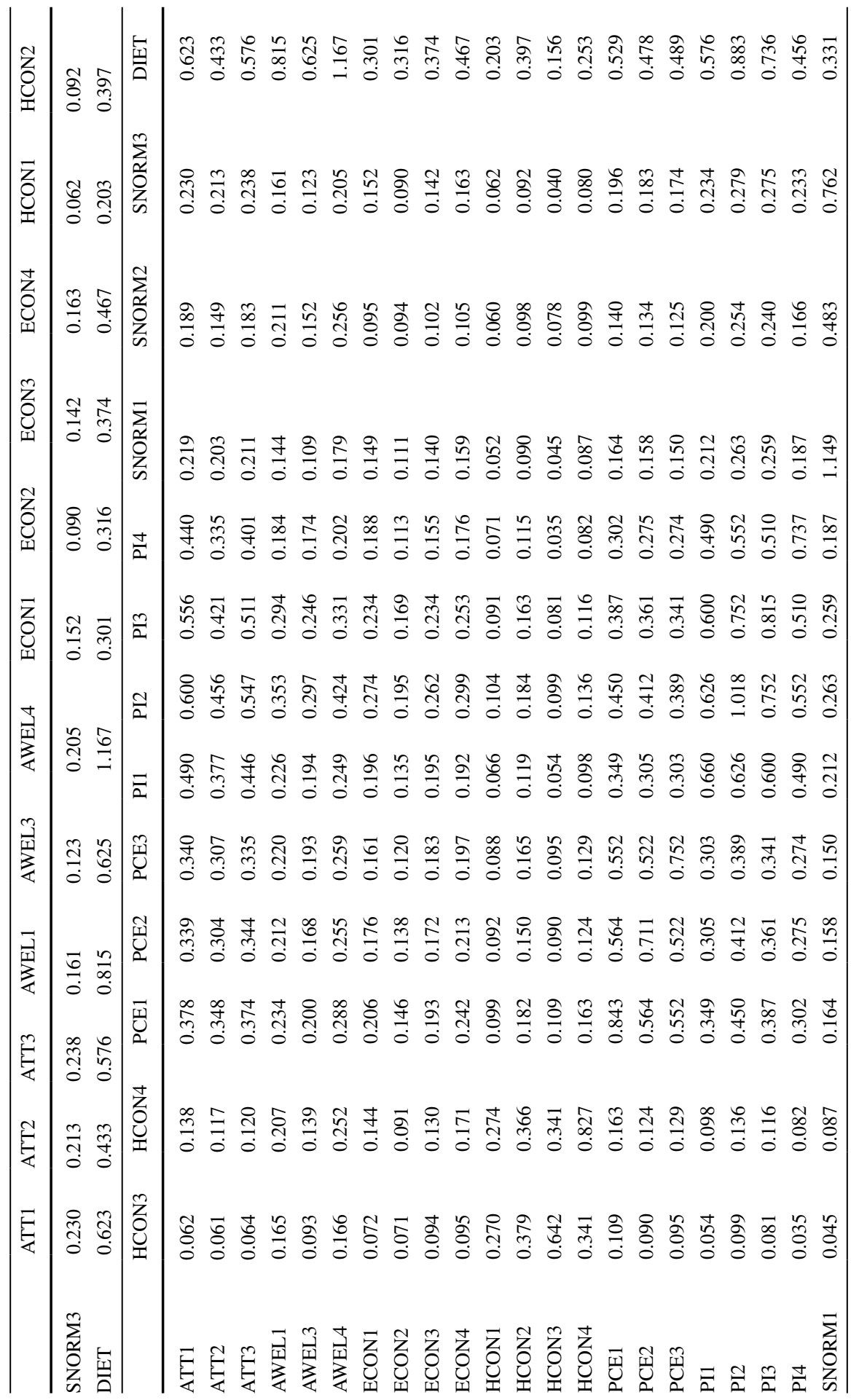




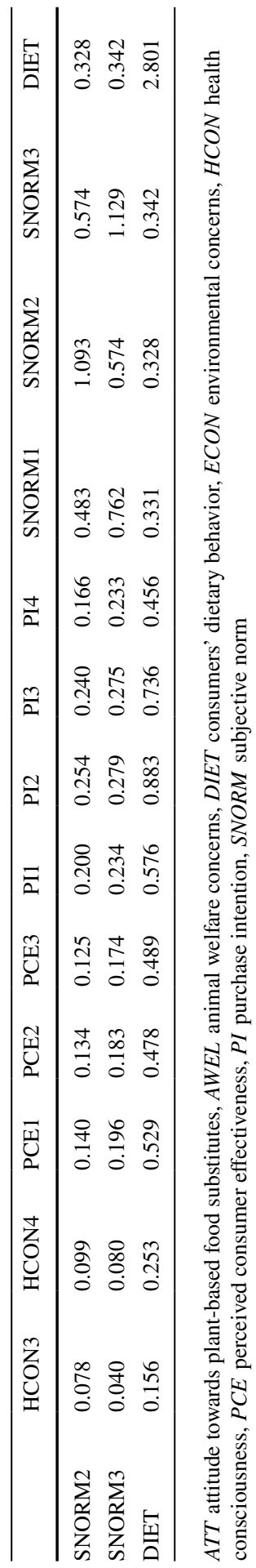




\section{Appendix B: Constructs and items (translated from German)}

\begin{tabular}{|c|c|c|c|}
\hline Construct & Item & & Loading \\
\hline \multirow{3}{*}{$\begin{array}{l}\text { Attitude towards } \\
\text { plant-based food } \\
\text { substitutes (ATT) }\end{array}$} & ATT1 & $\begin{array}{l}\text { I ... the idea of purchasing plant-based food substitutes } \\
\text { (dislike-like) }\end{array}$ & 0.932 \\
\hline & ATT2 & $\begin{array}{l}\text { Purchasing plant-based food substitutes is a ... idea (very } \\
\text { bad-very good) }\end{array}$ & 0.866 \\
\hline & ATT3 & $\begin{array}{l}\text { I have a ... attitude towards plant-based food substitutes } \\
\text { (very unfavorable-very favorable) }\end{array}$ & 0.890 \\
\hline \multirow[t]{3}{*}{$\begin{array}{l}\text { Animal welfares con- } \\
\text { cerns (AWEL) }\end{array}$} & AWEL1 & $\begin{array}{l}\text { I would rather buy more expensive animal products if } \\
\text { animals were treated better }\end{array}$ & 0.820 \\
\hline & AWEL3 & I do not purchase products for which animals had to suffer & 0.772 \\
\hline & AWEL4 & It is important to me that animals do not have to suffer & 0.822 \\
\hline \multirow[t]{3}{*}{$\begin{array}{l}\text { Perceived consumer } \\
\text { effectiveness (PCE) }\end{array}$} & PCE1 & $\begin{array}{l}\text { Purchasing plant-based food substitutes saves valuable } \\
\text { environmental resources }\end{array}$ & 0.868 \\
\hline & PCE2 & $\begin{array}{l}\text { I can protect the environment when purchasing plant- } \\
\text { based food substitutes }\end{array}$ & 0.845 \\
\hline & PCE3 & $\begin{array}{l}\text { I am able to decrease environmental problems with the } \\
\text { purchase of plant-based food substitutes }\end{array}$ & 0.818 \\
\hline \multirow{4}{*}{$\begin{array}{l}\text { Purchase intention } \\
\text { (PI) }\end{array}$} & PI1 & I will buy plant-based food substitutes in the future & 0.861 \\
\hline & PI2 & $\begin{array}{l}\text { I intend to buy plant-based food substitutes instead of } \\
\text { animal-based products in the future }\end{array}$ & 0.931 \\
\hline & PI3 & I consider buying plant-based food substitutes & 0.921 \\
\hline & PI4 & $\begin{array}{l}\text { I would consider purchasing plant-based food substitutes } \\
\text { if I happen to see them in a (grocery) store }\end{array}$ & 0.712 \\
\hline \multirow{3}{*}{$\begin{array}{l}\text { Subjective norm } \\
\text { (SNORM) }\end{array}$} & SNORM1 & My family expects me to buy plant-based food substitutes & 0.725 \\
\hline & SNORM2 & $\begin{array}{l}\text { People who are important to me expect me to buy plant- } \\
\text { based food substitutes }\end{array}$ & 0.696 \\
\hline & SNORM3 & My friends expect me to buy plant-based food substitutes & 0.789 \\
\hline \multirow[t]{4}{*}{$\begin{array}{l}\text { Environ-mental con- } \\
\text { cerns (ECON) }\end{array}$} & ECON1 & $\begin{array}{l}\text { I am concerned about the long-term consequences of non- } \\
\text { sustainable behavior }\end{array}$ & 0.622 \\
\hline & ECON2 & $\begin{array}{l}\text { I often think about the potential negative development of } \\
\text { the environmental situation }\end{array}$ & 0.732 \\
\hline & ECON3 & I am concerned about future environmental development & 0.830 \\
\hline & ECON4 & I am concerned to worsen our environment's quality & 0.805 \\
\hline \multirow[t]{4}{*}{$\begin{array}{l}\text { Health consciousness } \\
\text { (HCON) }\end{array}$} & HCON1 & $\begin{array}{l}\text { My health is so valuable to me that I am prepared to sacri- } \\
\text { fice many things for it }\end{array}$ & 0.656 \\
\hline & HCON2 & I consider myself very health-conscious & 0.919 \\
\hline & HCON3 & I think that I take health into account a lot in my life & 0.524 \\
\hline & HCON4 & I take care of my health & 0.714 \\
\hline
\end{tabular}




\section{Appendix C: Evaluation of the Fornell-Larcker criterion}

\begin{tabular}{lllllllll}
\hline & ATT & AWEL & DIET & ECON & HCON & PCE & PI & SNORM \\
\hline ATT & 0.932 & & & & & & & \\
AWEL & 0.351 & 0.875 & & & & & & \\
DIET & 0.439 & 0.601 & 1.000 & & & & & \\
ECON & 0.353 & 0.352 & 0.338 & 0.818 & & & & \\
HCON & 0.230 & 0.351 & 0.260 & 0.254 & 0.821 & & & \\
PCE & 0.587 & 0.336 & 0.379 & 0.347 & 0.252 & 0.899 & & \\
PI & 0.786 & 0.387 & 0.493 & 0.388 & 0.211 & 0.547 & 0.895 & \\
SNORM & 0.314 & 0.225 & 0.226 & 0.217 & 0.134 & 0.229 & 0.331 & 0.834 \\
\hline
\end{tabular}

ATT attitude towards plant-based food substitutes, AWEL animal welfare concerns, DIET consumers' dietary behavior, ECON environmental concerns, $H C O N$ health consciousness, $P C E$ perceived consumer effectiveness, $P I$ purchase intention, SNORM subjective norm.

\section{Appendix D: Cross-loadings}

\begin{tabular}{lllllllll}
\hline & ATT & AWEL & ECON & HCON & PCE & PI & SNORM & DIET \\
\hline ATT1 & $\mathbf{0 . 9 3 3}$ & 0.338 & 0.352 & 0.224 & 0.531 & 0.774 & 0.287 & 0.443 \\
ATT2 & $\mathbf{0 . 9 2 7}$ & 0.307 & 0.325 & 0.207 & 0.567 & 0.694 & 0.299 & 0.362 \\
ATT3 & $\mathbf{0 . 9 3 5}$ & 0.336 & 0.308 & 0.213 & 0.544 & 0.726 & 0.292 & 0.420 \\
AWEL1 & 0.306 & $\mathbf{0 . 9 0 1}$ & 0.338 & 0.335 & 0.303 & 0.353 & 0.208 & 0.523 \\
AWEL3 & 0.331 & $\mathbf{0 . 8 5 0}$ & 0.346 & 0.279 & 0.297 & 0.356 & 0.181 & 0.469 \\
AWEL4 & 0.288 & $\mathbf{0 . 8 7 3}$ & 0.245 & 0.305 & 0.282 & 0.311 & 0.200 & 0.580 \\
ECON1 & 0.278 & 0.201 & $\mathbf{0 . 7 4 9}$ & 0.126 & 0.253 & 0.306 & 0.166 & 0.198 \\
ECON2 & 0.253 & 0.288 & $\mathbf{0 . 8 2 2}$ & 0.216 & 0.268 & 0.298 & 0.173 & 0.295 \\
ECON3 & 0.317 & 0.318 & $\mathbf{0 . 8 6 2}$ & 0.243 & 0.310 & 0.353 & 0.194 & 0.299 \\
ECON4 & 0.304 & 0.329 & $\mathbf{0 . 8 3 6}$ & 0.231 & 0.300 & 0.311 & 0.176 & 0.303 \\
HCON1 & 0.153 & 0.255 & 0.171 & $\mathbf{0 . 8 1 8}$ & 0.171 & 0.149 & 0.095 & 0.176 \\
HCON2 & 0.219 & 0.339 & 0.228 & $\mathbf{0 . 8 9 3}$ & 0.245 & 0.211 & 0.123 & 0.277 \\
HCON4 & 0.186 & 0.255 & 0.222 & $\mathbf{0 . 7 4 6}$ & 0.193 & 0.148 & 0.110 & 0.166 \\
PCE1 & 0.542 & 0.307 & 0.326 & 0.240 & $\mathbf{0 . 9 0 1}$ & 0.505 & 0.207 & 0.345 \\
PCE2 & 0.529 & 0.294 & 0.316 & 0.218 & $\mathbf{0 . 9 0 6}$ & 0.500 & 0.213 & 0.339 \\
PCE3 & 0.512 & 0.304 & 0.292 & 0.222 & $\mathbf{0 . 8 9 0}$ & 0.470 & 0.196 & 0.337 \\
PI1 & 0.728 & 0.324 & 0.338 & 0.174 & 0.498 & $\mathbf{0 . 9 2 0}$ & 0.300 & 0.424 \\
PI2 & 0.716 & 0.417 & 0.389 & 0.212 & 0.525 & $\mathbf{0 . 9 0 5}$ & 0.298 & 0.523 \\
PI3 & 0.743 & 0.378 & 0.377 & 0.208 & 0.511 & $\mathbf{0 . 9 2 8}$ & 0.324 & 0.487 \\
PI4 & 0.618 & 0.257 & 0.277 & 0.158 & 0.420 & $\mathbf{0 . 8 2 4}$ & 0.259 & 0.317 \\
SNORM1 & 0.267 & 0.157 & 0.199 & 0.106 & 0.186 & 0.268 & $\mathbf{0 . 8 4 2}$ & 0.185 \\
SNORM2 & 0.224 & 0.230 & 0.147 & 0.121 & 0.162 & 0.257 & $\mathbf{0 . 7 6 6}$ & 0.188 \\
\hline
\end{tabular}




\begin{tabular}{lllllllll}
\hline & ATT & AWEL & ECON & HCON & PCE & PI & SNORM & DIET \\
\hline SNORM3 & 0.290 & 0.179 & 0.194 & 0.110 & 0.220 & 0.300 & $\mathbf{0 . 8 8 9}$ & 0.193 \\
DIET & 0.439 & 0.601 & 0.338 & 0.260 & 0.379 & 0.493 & 0.226 & $\mathbf{1 . 0 0 0}$ \\
\hline
\end{tabular}

Loadings of indicators on their assigned constructs are highlighted in bold

ATT attitude towards plant-based food substitutes, AWEL animal welfare concerns, DIET consumers' dietary behavior, ECON environmental concerns, $H C O N$ health consciousness, $P C E$ perceived consumer effectiveness, $P I$ purchase intention, SNORM subjective norm.

Funding Open Access funding enabled and organized by Projekt DEAL. This research did not receive any specific grant from funding agencies in the public, commercial, or not-for-profit sectors.

Code availability Not applicable.

Availability of data and material No data is provided.

\section{Declarations}

Conflicts of interest The authors disclose that they have no conflict of interest.

Open Access This article is licensed under a Creative Commons Attribution 4.0 International License, which permits use, sharing, adaptation, distribution and reproduction in any medium or format, as long as you give appropriate credit to the original author(s) and the source, provide a link to the Creative Commons licence, and indicate if changes were made. The images or other third party material in this article are included in the article's Creative Commons licence, unless indicated otherwise in a credit line to the material. If material is not included in the article's Creative Commons licence and your intended use is not permitted by statutory regulation or exceeds the permitted use, you will need to obtain permission directly from the copyright holder. To view a copy of this licence, visit http://creativecommons.org/licen ses/by/4.0/.

\section{References}

Abrahamse W, Steg L (2013) Social influence approaches to encourage resource conservation: a metaanalysis. Glob Environ Chang 23:1773-1785

Agriculture and Agri-Food Canada (2017) Vegetarian and Vegan Food in Germany. https://www.agr.gc. ca/resources/prod/Internet-Internet/MISB-DGSIM/ATS-SEA/PDF/6840-eng.pdf

Ajzen I (1985) From intentions to actions: a theory of planned behavior. In: Kuhl J, Beckmann J (eds) Action control: from cognition to behavior, 1st edn. Springer, Berlin, pp 11-39

Ajzen I (1988) Attitudes, Personality and Behavior. Open University Press, Milton Keynes

Ajzen I (1991) The theory of planned behavior. Organ Behav Hum Decis Process 50:179-211. https:// doi.org/10.1016/0749-5978(91)90020-t

Ajzen I (2001) Nature and operation of attitudes. Annu Rev Psychol 52:27-58. https://doi.org/10.1146/ annurev.psych.52.1.27

Ajzen I, Driver BL (1991) Prediction of leisure participation from behavioral, normative, and control beliefs: an application of the theory of planned behavior. Leis Sci 13:185-204. https://doi.org/10. 1080/01490409109513137

Ajzen I, Fishbein M (1980) Understanding attitudes and predicting social behavior. Prentice-Hall, Englewood Cliffs 
Ajzen I, Madden TJ (1986) Prediction of goal-directed behavior: attitudes, intentions, and perceived behavioral control. J Exp Soc Psychol 22:453-474. https://doi.org/10.1016/0022-1031(86)90045-4

Anderson WT, Cunningham WH (1972) The socially conscious consumer. J Mark 36:23-31. https://doi. org/10.1177/002224297203600305

Antil JH (1984) Socially responsible consumers: profile and implications for public policy. J Macromark 4:18-39. https://doi.org/10.1177/027614678400400203

Bandura A (1982) Self-efficacy mechanism in human agency. Am Psychol 37:122-147. https://doi.org/ 10.1037/0003-066X.37.2.122

Benitez J, Henseler J, Castillo A, Schuberth F (2020) How to perform and report an impactful analysis using partial least squares: Guidelines for confirmatory and explanatory IS research. Inf Manag 57:103168. https://doi.org/10.1016/j.im.2019.05.003

Berger IE, Corbin RM (1992) Perceived consumer effectiveness and faith in others as moderators of environmentally responsible behaviors. J Public Policy Mark 11:79-89. https://doi.org/10.1177/07439 1569201100208

Chan RYK (2001) Determinants of Chinese consumers' green purchase behavior. Psychol Mark 18:389_ 413. https://doi.org/10.1002/mar.1013

Corrin T, Papadopoulos A (2017) Understanding the attitudes and perceptions of vegetarian and plantbased diets to shape future health promotion programs. Appetite 109:40-47. https://doi.org/10. 1016/j.appet.2016.11.018

Davies A, Titterington AJ, Cochrane C (1995) Who buys organic food? Br Food J 97:17-23. https://doi. org/10.1108/00070709510104303

de Boer J, Schösler H, Aiking H (2017) Towards a reduced meat diet: mindset and motivation of young vegetarians, low, medium and high meat-eaters. Appetite 113:387-397. https://doi.org/10.1016/j. appet.2017.03.007

Dijkstra TK, Henseler J (2015) Consistent partial least squares path modeling. MIS Q 39:297-316

Dul J (2016a) Identifying single necessary conditions with NCA and fsQCA. J Bus Res 69:1516-1523

Dul J (2016b) Necessary condition analysis (NCA) logic and methodology of "necessary but not sufficient" causality. Organ Res Methods 19:10-52

Dunlap RE, van Liere KD, Mertig AG, Jones RE (2000) New trends in measuring environmental attitudes: measuring endorsement of the new ecological paradigm: a revised NEP scale. J Soc Issues 56:425-442. https://doi.org/10.1111/0022-4537.00176

Dyett PA, Sabaté J, Haddad E, Rajaram S, Shavlik D (2013) Vegan lifestyle behaviors: an exploration of congruence with health-related beliefs and assessed health indices. Appetite 67:119-124. https:// doi.org/10.1016/j.appet.2013.03.015

Ellen PS, Wiener JL, Cobb-Walgren C (1991) The role of perceived consumer effectiveness in motivating environmentally conscious behaviors. J Public Policy Mark 10:102-117. https://doi.org/10.1177/ 074391569101000206

Fishbein M, Ajzen I (1975) Belief, attitude, intention, and behavior: an introduction to theory and research. Addison-Wesley, Reading

Fox N, Ward K (2008) Health, ethics and environment: a qualitative study of vegetarian motivations. Appetite 50:422-429. https://doi.org/10.1016/j.appet.2007.09.007

Goh SK, Balaji MS (2016) Linking green skepticism to green purchase behavior. J Clean Prod 131:629-638

Gould SJ (1988) Consumer attitudes toward health and health care: a differential perspective. J Consum Aff 22:96-118. https://doi.org/10.1111/j.1745-6606.1988.tb00215.x

Hair JF, Risher JJ, Sarstedt M, Ringle CM (2019) When to use and how to report the results of PLS-SEM. Eur Bus Rev 31:2-24

Hair JF Jr, Howard MC, Nitzl C (2020) Assessing measurement model quality in PLS-SEM using confirmatory composite analysis. J Bus Res 109:101-110

Harper GC, Makatouni A (2002) Consumer perception of organic food production and farm animal welfare. Br Food J 104:287-299. https://doi.org/10.1108/00070700210425723

Henseler J, Ringle CM, Sarstedt M (2015) A new criterion for assessing discriminant validity in variance-based structural equation modeling. J Acad Mark Sci 43:115-135

Henseler J, Hubona G, Ray PA (2016) Using PLS path modeling in new technology research: updated guidelines. Ind Manag Data Syst 116:2-20

Hill H, Lynchehaun F (2002) Organic milk: attitudes and consumption patterns. Br Food J 104:526-542. https://doi.org/10.1108/00070700210434570 
Hughner RS, McDonagh P, Prothero A, Shultz CJ, Stanton J (2007) Who are organic food consumers? A compilation and review of why people purchase organic food. J Consum Behav 6:94-110. https:// doi.org/10.1002/cb. 210

Institute of Mechanical Engineers (2013) Global Food Report: Waste not, Want not. https://www.imeche. org/docs/default-source/reports/Global_Food_Report.pdf

Jabs J, Devine CM, Sobal J (1998) Model of the process of adopting vegetarian diets: health vegetarians and ethical vegetarians. J Nutr Educ 30:196-202. https://doi.org/10.1016/S0022-3182(98)70319-X

Jaiswal D, Kant R (2018) Green purchasing behaviour: a conceptual framework and empirical investigation of Indian consumers. J Retail Consum Serv 41:60-69. https://doi.org/10.1016/j.jretconser.2017. 11.008

Janssen M, Busch C, Rödiger M, Hamm U (2016) Motives of consumers following a vegan diet and their attitudes towards animal agriculture. Appetite 105:643-651. https://doi.org/10.1016/j.appet.2016. 06.039

Kautish P, Sharma R (2019) Value orientation, green attitude and green behavioral intentions: an empirical investigation among young consumers. Young Consumers 20:338-358. https://doi.org/10.1108/ YC-11-2018-0881

Kautish P, Sharma R (2020) Determinants of pro-environmental behavior and environmentally conscious consumer behavior: An empirical investigation from emerging market. Bus Strategy Develop 3:112-127

Kautish P, Paul J, Sharma R (2019) The moderating influence of environmental consciousness and recycling intentions on green purchase behavior. J Clean Prod 228:1425-1436. https://doi.org/10.1016/j. jclepro.2019.04.389

Kinnear TC, Taylor JR, Ahmed SA (1974) Ecologically concerned consumers: Who are they? J Mark 38:20-24. https://doi.org/10.1177/002224297403800205

Kock N (2015) Common method bias in PLS-SEM: A full collinearity assessment approach. Int J e-Collab 11:1-10

Kraft FB, Goodell PW (1993) Identifying the health conscious consumer. J Health Care Mark 13:18-25

Latvala T, Niva M, Mäkelä J, Pouta E, Heikkilä J, Kotro J, Forsman-Hugg S (2012) Diversifying meat consumption patterns: consumers' self-reported past behaviour and intentions for change. Meat Sci 92:71-77. https://doi.org/10.1016/j.meatsci.2012.04.014

Lea E, Worsley A (2001) Influences on meat consumption in Australia. Appetite 36:127-136. https://doi. org/10.1006/appe.2000.0386

Lea EJ, Crawford D, Worsley A (2006a) Consumers' readiness to eat a plant-based diet. Eur J Clin Nutr 60:342-351. https://doi.org/10.1038/sj.ejcn.1602320

Lea EJ, Crawford D, Worsley A (2006b) Public views of the benefits and barriers to the consumption of a plant-based diet. Eur J Clin Nutr 60:828-837. https://doi.org/10.1038/sj.ejcn.1602387

Lee K (2008) Opportunities for green marketing: young consumers. Marketing Intell Plan 26:573-586. https://doi.org/10.1108/02634500810902839

Liska AE (1984) A critical examination of the causal structure of the Fishbein/Ajzen attitude-behavior model. Social Psychol Q 47:61-74. https://doi.org/10.2307/3033889

Macdiarmid JI, Douglas F, Campbell J (2016) Eating like there's no tomorrow: public awareness of the environmental impact of food and reluctance to eat less meat as part of a sustainable diet. Appetite 96:487-493. https://doi.org/10.1016/j.appet.2015.10.011

Magnusson MK, Arvola A, Hursti U-KK, Åberg L, Sjödén P-O (2001) Attitudes towards organic foods among Swedish consumers. Br Food J 103:209-227. https://doi.org/10.1108/00070700110386755

Maloney MP, Ward MP, Braucht GN (1975) A revised scale for the measurement of ecological attitudes and knowledge. Am Psychol 30:787-790. https://doi.org/10.1037/h0084394

Michaelidou N, Hassan LM (2008) The role of health consciousness, food safety concern and ethical identity on attitudes and intentions towards organic food. Int J Cons Stud 32:163-170. https://doi. org/10.1111/j.1470-6431.2007.00619.x

Mostafa MM (2007) A hierarchical analysis of the green consciousness of the Egyptian consumer. Psychol Mark 24:445-473. https://doi.org/10.1002/mar.20168

Mullee A, Vermeire L, Vanaelst B, Mullie P, Deriemaeker P, Leenaert T, de Henauw S, Dunne A, Gunter MJ, Clarys P, Huybrechts I (2017) Vegetarianism and meat consumption: a comparison of attitudes and beliefs between vegetarian, semi-vegetarian, and omnivorous subjects in Belgium. Appetite 114:299-305. https://doi.org/10.1016/j.appet.2017.03.052 
Newsom JT, McFarland BH, Kaplan MS, Huguet N, Zani B (2005) The health consciousness myth: implications of the near independence of major health behaviors in the North American population. Soc Sci Med 60:433-437. https://doi.org/10.1016/j.socscimed.2004.05.015

Park HJ, Lin LM (2018) Exploring attitude-behavior gap in sustainable consumption: comparison of recycled and upcycled fashion products. J Bus Res 117:623-628

PBFA, GFI (2020) U.S. Plant-Based Retail Market Worth \$5 Billion, Growing at 5X Total Food Sales. https://plantbasedfoods.org/plant-based-foods-retail-sales-data-2020/

Petty RE, Unnava RH, Stratham AJ (1991) Theories of attitude change. In: Robertson TS, Kassarjian HH (eds) Handbook of consumer behavior. Prentice-Hall, Englewood Cliffs, pp 241-280

Podsakoff PM, Organ DW (1986) Self-reports in organizational research: problems and prospects. J Manag 12:531-544

Pohjolainen P, Vinnari M, Jokinen P (2015) Consumers' perceived barriers to following a plant-based diet. British Food Journal 117:1150-1167. https://doi.org/10.1108/BFJ-09-2013-0252

Povey R, Wellens B, Conner M (2001) Attitudes towards following meat, vegetarian and vegan diets: an examination of the role of ambivalence. Appetite 37:15-26. https://doi.org/10.1006/appe.2001.0406

Prakash G, Pathak P (2017) Intention to buy eco-friendly packaged products among young consumers of India: a study on developing nation. J Clean Prod 141(385):393

Rausch TM, Kopplin CS (2021) Bridge the gap: Consumers' purchase intention and behavior regarding sustainable clothing. J Clean Prod 278:123882

Richter NF, Schubring S, Hauff S, Ringle CM, Sarstedt M (2020) When predictors of outcomes are necessary: guidelines for the combined use of PLS-SEM and NCA. IMDS Ahead-of-Print. https://doi. org/10.1108/IMDS-11-2019-0638

Ringle CM, Wende S, Becker J-M (2015) SmartPLS 3. SmartPLS GmbH, Boenningstedt. http://www. smartpls.com

Roberts JA (1996) Green consumers in the 1990s: profile and implications for advertising. J Bus Res $36: 217-231$

Schifferstein HNJ, Oude Ophuis PAM (1998) Health-related determinants of organic food consumption in The Netherlands. Food Qual Prefer 9:119-133. https://doi.org/10.1016/S0950-3293(97)00044-X

Sharma A, Joshi S (2017) Green consumerism: overview and further research directions. Int J Process Manag Benchmark 7:206-223

Shepherd R, Towler G (2007) Nutrition knowledge, attitudes and fat intake: application of the theory of reasoned action. J Hum Nutr Diet 20:159-169. https://doi.org/10.1111/j.1365-277X.2007.00776.x

Singh A, Verma P (2017) Factors influencing Indian consumers' actual buying behaviour towards organic food products. J Clean Prod 167:473-483. https://doi.org/10.1016/j.jclepro.2017.08.106

Smith S, Paladino A (2010) Eating clean and green? Investigating consumer motivations towards the purchase of organic food. Australas Mark J 18:93-104. https://doi.org/10.1016/j.ausmj.2010.01.001

Squires L, Juric B, Bettina Cornwell T (2001) Level of market development and intensity of organic food consumption: cross-cultural study of Danish and New Zealand consumers. J Consum Mark 18:392409. https://doi.org/10.1108/07363760110398754

Stern PC, Dietz T, Kalof L (1993) Value Orientations, Gender, and Environmental Concern. Environ Behav 25:322-348. https://doi.org/10.1177/0013916593255002

Tarkiainen A, Sundqvist S (2005) Subjective norms, attitudes and intentions of Finnish consumers in buying organic food. Br Food J 107:808-822. https://doi.org/10.1108/00070700510629760

Taufique KMR, Vaithianathan S (2018) A fresh look at understanding Green consumer behavior among young urban Indian consumers through the lens of theory of planned behavior. J Clean Prod 183:46-55

Taylor S, Todd P (1995) Understanding household garbage reduction behavior: a test of an integrated model. J Public Policy Mark 14:192-204. https://doi.org/10.1177/074391569501400202

Thogersen J (2009) Consumer decision-making with regard to organic food products. In: Vaz TdN, Nijkamp P, Rastoin J-L (eds) Traditional food production and rural sustainable development: a European challenge. Ashgate, Farnham UK, pp 173-194

Tregear A, Dent JB, McGregor MJ (1994) The Demand for Organically Grown Produce. Br Food J 96:21-25. https://doi.org/10.1108/00070709410061032

Vermeir I, Verbeke W (2006) Sustainable food consumption: exploring the consumer "attitude—behavioral intention" gap. J Agric Environ Ethics 19:169-194. https://doi.org/10.1007/s10806-005-5485-3

Vermeir I, Verbeke W (2008) Sustainable food consumption among young adults in Belgium: theory of planned behaviour and the role of confidence and values. Ecol Econ 64:542-553. https://doi.org/10. 1016/j.ecolecon.2007.03.007 
Webb TL, Sheeran P (2006) Does changing behavioral intentions engender behavior change? A metaanalysis of the experimental evidence. Psychol Bull 132:249-268. https://doi.org/10.1037/00332909.132.2.249

Webster JFE (1975) Determining the characteristics of the socially conscious consumer. J Consum Res 2:188. https://doi.org/10.1086/208631

Weigel R, Weigel J (1978) Environmental Concern. Environ Behav 10:3-15. https://doi.org/10.1177/ 0013916578101001

Weisberg YJ, DeYoung CG, Hirsh JB (2011) Gender differences in personality across the ten aspects of the Big Five. Front Psychol 2:178-188

White K, Habib R, Hardisty DJ (2019) How to SHIFT consumer behaviors to be more sustainable: a literature review and guiding framework. J Mark 83:22-49. https://doi.org/10.1177/0022242919825649

Woodside AG (2013) Moving beyond multiple regression analysis to algorithms: calling for adoption of a paradigm shift from symmetric to asymmetric thinking in data analysis and crafting theory. $\mathrm{J}$ Bus Res 66:463-472

Yadav R, Pathak GS (2016) Young consumers' intention towards buying green products in a developing nation: Extending the theory of planned behavior. J Clean Prod 135:732-739. https://doi.org/10. 1016/j.jclepro.2016.06.120

Yadav R, Pathak GS (2017) Determinants of consumers' green purchase behavior in a developing nation: applying and extending the theory of planned behavior. Ecol Econ 134:114-122. https://doi.org/10. 1016/j.ecolecon.2016.12.019

Publisher's Note Springer Nature remains neutral with regard to jurisdictional claims in published maps and institutional affiliations. 